\title{
Patterns of Genetic Diversity in the Globally Invasive Species Wild Parsnip (Pastinaca sativa)
}

\author{
Tania Jogesh, Rhiannon Peery, Stephen R. Downie, and May R. Berenbaum*
}

\begin{abstract}
Wild parsnip is an invasive species with a global distribution in temperate climates. Parsnips are native to Eurasia and have been cultivated for more than five centuries. It is unclear whether the global invasion of this species is a consequence of escape from cultivation or the accidental introduction of a Eurasian wild subspecies. In this study, we used nuclear ribosomal DNA internal transcribed spacer (ITS) and chloroplast DNA (cpDNA) markers to evaluate the genetic structure of wild parsnip in its native range (Europe) and in three distinct geographic regions where it is considered invasive: eastern North America, western North America, and New Zealand. We also compared wild and cultivated parsnips to determine whether they are genetically distinct. From 112 individuals, we recovered 14 ITS and 27 cpDNA haplotypes. One ITS haplotype was widespread; few haplotypes were rare singletons. In contrast, at least two lineages of cpDNA haplotypes were recovered, with several novel haplotypes restricted to Europe. Cultivated parsnips were not genetically distinct from wild parsnips, and numerous wild parsnip populations shared haplotypes with cultivars. High genetic diversity was recovered in all three regions, suggesting multiple introductions.
\end{abstract}

Nomenclature: Wild parsnip, Pastinaca sativa L. PASA2.

Key words: Chloroplast haplotypes, colonization history, cultivars, invasion genetics, New Zealand.

A major consequence of international trade is the recurrent establishment of invasive species on a global scale. Invasive species can be extremely detrimental to native ecosystems and are considered a leading threat to biodiversity worldwide (Pysek et al. 2012; Pysek and Richardson 2011; Vilà et al. 2011). Tracking the source population and invasion routes is the first step in designing effective management strategies (Schaal et al. 2003). Historical documentation and real-time observations of invasions are rare, but advances in molecular methods and tools for population genetics have made it possible to reconstruct the colonization history of invasive populations (Lombaert et al. 2011). These techniques have been used with increasing

DOI: $10.1614 /$ IPSM-D-15-00024.1

* First and fourth authors: Graduate Student and Professor, Department of Entomology, University of Illinois Urbana-Champaign, 320 Morrill Hall, 505 S. Goodwin Avenue, Urbana, IL 61820; second and third authors: Graduate Student and Professor, Department of Plant Biology, University of Illinois Urbana-Champaign, 265 Morrill Hall, 505 S. Goodwin Avenue, Urbana, IL 61820. Current address of first author: Postdoctoral Researcher, Plant Conservation Science, Chicago Botanic Garden, 1000 Lake Cook Road, Glencoe, IL 60022. Corresponding author E-mail: tjogesh@chicagobotanic.org frequency to analyze the genetic structure of introduced populations, to make inferences about their origins, and to determine routes of establishment (reviewed in Estoup and Guillmaud 2010). Recent studies that have examined the genetic relationship between closely related, wild and cultivated species suggest that cultivation has an important role in influencing the spread of invasive weeds. Naturalized cultivars might become invasive or introgressive with closely related wild and cultivated species and might produce invasive hybrids. For example, invasive orange wattle [Acacia saligna (Labill.) Wendl. f.] (Fabaceae) in South Africa is more closely related to a cultivated variety in Western Australia than it is to its wild Australian counterpart (Thompson et al. 2012). Invasive wild radish (Raphanus raphanistrum L.) (Brassicaceae) frequently hybridizes with cultivated radish (Raphanus sativus L.) in California (Ridley et al. 2008) and potentially in South Africa (Barnaud et al. 2013). Nineteen percent of wild grape [Vitis vinifera L. subsp. sylvestris (C.C. Gmel.) Hegi] (Vitaceae) comprises naturalized cultivars in Spain (DeAndreas et al. 2012). Cultivars are likely associated with the origin and spread of many invasive species.

Wild parsnip (Pastinaca sativa L.) (Apiaceae) is an herbaceous, biennial native of Europe that now occurs on every continent, except Antarctica (Averill and DiTommaso 2007). Parsnips are believed to have originated in the Caucasus 


\section{Management Implications}

The availability of molecular data and advances in population genetic analysis have made it possible to estimate the patterns of species migrations with considerable precision. Findings from historical colonization and dispersal studies can shed light on human-mediated transport of biological materials and provide a broad understanding of how humans may have contributed to the introduction and spread of an invasive species. Evidence obtained in this study indicates that escape from cultivation led to the globalization of wild parsnips and introduced populations have high genetic diversity. Increased levels of diversity in invasive populations can act as a primer for rapid adaptive evolution of this noxious invasive species. Future studies with increased sampling and additional loci have the potential to elucidate specific patterns of colonization and admixture in this agriculturally entwined invasive plant and may serve as a model for investigating the natural and agricultural history of plant species that exist in wild, cultivated, and feral forms.

Mountains, a center of diversity for the genus Pastinaca (Rubatzky et al. 1999). However, P. sativa is the only species in the genus to occur outside Europe, and its spread throughout the world may have been linked to its cultivation as a food crop. The long, carbohydrate-rich taproot produced by cultivated varieties of this species is frequently consumed in many parts of the world. Parsnips are currently cultivated commercially on at least three continents (North America, Europe, and Oceania) and, in all three regions, wild parsnips occur as an invasive species (Averill and DiTommaso 2007). The distinction between a wild and a cultivated parsnip is unclear. Some sources cite the cultivated parsnip Pastinaca sativa subsp. sativa as a distinct subspecies from its wild counterpart, Pastinaca sativa subsp. sylvestris (Mill.) Rouy \& E.G. Camus, because of physical and chemical differences (Averill and DiTommaso 2007; Berenbaum et al. 1984). Wild parsnips are considered invasive because they are a nuisance to humans and livestock; they also present an aggressive threat to a variety of natural communities once they become established and can displace native species (Averill and DiTommaso 2007). Roots of wild parsnips are tough and can be poisonous because of the production of large quantities of myristicin, a hallucinogenic phenylpropanoid (Stahl 1981). Aboveground structures of wild parsnips also contain higher concentrations of the photodermatitis-inducing furanocoumarins compared with cultivated varieties (Berenbaum et al. 1984). These furanocoumarins are demonstrably allelopathic in related umbellifers and may allow wild parsnips to grow in large monocultures and outcompete other species (Juntilla 1976). In spite of the phenotypic differences, the evolutionary origins of, and taxonomic distinctions between, the two forms have never, to our knowledge, been fully examined.
The history of parsnip domestication from its wild progenitor is obscure. Historically, the name Pastinaca may have referred to parsnip or to carrot (Daucus carota L. var. sativus Hoffm.), and there is some evidence that both were cultivated and consumed in ancient Greece (Hedrick and Sturtevant 1972). Parsnip seeds have been recovered in a Neolithic Swiss lake dwelling, dating back 4000 years, possibly the earliest evidence of parsnip cultivation (Weaver 1997). The cultivation of parsnips, as distinct from carrots, has been documented with some certainty throughout Europe in the 14th century, in South America (Venezuela) in 1564, and in 1604, in Peru (Averill and DiTommaso 2007). In North America, Native Americans purportedly used the roots for medicinal purposes as early as 1606 (Hedrick and Sturtevant 1972). Modern varieties of cultivated parsnips can be traced to the $P$. sativa 'Student' cultivar selectively bred from wild parsnips in 1849 by Professor James Buckman at the Royal Agricultural College, Cirencester, England (Buckman 1865). At least one parsnip cultivar from Surrey, England, P. sativa 'Gladiator', is a known hybrid between a cultivated parsnip and a wild parsnip.

In eastern North America, cultivars may have escaped soon after introduction in the early 17 th century (Sturtevant 1890). The earliest herbarium record for wild parsnips in the United States dates back to 1822, and the specimen was collected near Hamden, CT (GBIF data portal, 2015). In the western United States, although no historical information is available on dates of arrival, earliest herbarium records of $P$. sativa date back to 1879 . Herbarium records indicate that by 1930 wild parsnips occurred throughout the lower 48 U.S. states (GBIF data portal, 2015; NANSH, 2015). Compared with the eastern United States, wild parsnip is uncommon in the western United States, with most populations occurring in disturbed agricultural settings ( $\mathrm{P}$. Ode, personal communication). In North America, wild parsnips currently occur in 45 of the 50 U.S. states and in all Canadian provinces and territories, except Nunavut and the Northwest Territories (Averill and DiTommaso 2007). It also occurs as an invasive species in southern South America, South Africa, China, Australia, and New Zealand. In New Zealand, the first written record of wild parsnip can be dated to 1867 (Webb 1978).

In this study, we used molecular markers to examine the relationship between wild parsnips and modern parsnip cultivars, as well as to evaluate patterns of genetic diversity among wild parsnips in eastern North America, western North America, and New Zealand-regions that have been colonized by this invasive plant. Two loci were analyzed: the nuclear ribosomal DNA internal transcribed spacer (ITS) region and the chloroplast DNA (cpDNA) $p s b M-\operatorname{trn} T$ region. Specifically, we wanted to identify (1) whether the genetic diversity of wild parsnips in the three study regions has been influenced by founder effects (alteration or reduction or both in genetic diversity) during 
introduction and invasion, (2) whether native European wild parsnips ( $P$. sativa subsp. sylvestris) are genetically distinct from modern cultivars ( $P$. sativa subsp. sativa), and (3) whether North American and New Zealand invasive populations are more closely related to modern cultivars or European wild parsnips

\section{Materials and Methods}

Sample Collection. Samples for DNA analysis were obtained from single leaves of individual plants. Pastinaca sativa samples were obtained from 58 sites in Europe, 27 sites in eastern North America, 8 sites in western North America, and 9 sites in the South Island of New Zealand (Table 1).

Each site consisted of a wild parsnip population isolated from other populations by either anthropogenic/geographic barriers or at least $20 \mathrm{~km}$ distance. Ten samples were collected at each site, but a preliminary analysis showed no variation in samples within sites for both loci, so only one sample per site was analyzed. Both ITS and cpDNA were included in the preliminary analysis, and we examined four individuals from the TOW population and three from the OCE population in New Zealand, three from the SWISS3 population in Europe, four from the IOW1 population, and three from the MAU2 population in the eastern United States (population information in Table 1). We found no variation at both loci in all these populations. All regions except the western United States were analyzed. The sampling effort was in proportion to available populations, with more samples in Europe and eastern North America, and fewer samples in western North America and New Zealand. One leaf per plant was collected and placed in a standard $(10.2 \mathrm{~cm}$ by $22.9 \mathrm{~cm})$ paper envelope and dried in a field press for $60 \mathrm{~d}$. In New Zealand, dried seeds were collected by Dr. Margaret Stanley (University of Auckland) and shipped to the University of Illinois at UrbanaChampaign (UIUC). New Zealand seeds were planted in the UIUC Department of Entomology greenhouse, and leaf material was collected approximately $4 \mathrm{wk}$ after germination and dried in a field press. Field collections were supplemented by leaf material obtained from $P$. sativa herbarium specimens (Illinois Plant Biology Herbarium and Illinois Natural History Survey Herbarium) and previously isolated DNA available in the Downie laboratory (Table 1). We also included previously isolated DNA from Pastinaca sativa subsp. urens (Godron) Cělak, Pastinaca sativa subsp. divaricata (Desf.) Rouy \& Camus, and Pastinaca pimpinellifolia M. Bieb. In addition, we planted six varieties of cultivated parsnips in the UIUC Department of Entomology greenhouse and collected leaf tissue from rosettes approximately $1 \mathrm{mo}$ after germination. Parsnip cultivars analyzed in this study were acquired from the United States and New Zealand; the cultivars 'All-American
Organic' (Todds Seeds, Novi, MI), 'US Hollowcrown' (Burpee Seeds, Warminster, PA), 'All-American Heirloom' (Botanical Interest, Broomfield, CO), and 'Excalibur' (Thompson and Morgan, Ipswich, England) were purchased in the United States, and cultivars 'Melbourne Whiteskin' (McGregor's, Auckland, New Zealand) and 'New Zealand Supersnip' (McGregor's) were purchased in New Zealand.

Molecular Markers. Two loci, ITS and $p s b M-t r n T$, were used to determine the diversity and distribution of haplotypes across geographic regions and cultivars. The ITS locus consists of two segments: ITS1, which is located between the $18 \mathrm{~S}$ and $5.8 \mathrm{~S}$ ribosomal genes, and ITS2, between the $5.8 \mathrm{~S}$ and $28 \mathrm{~S}$ ribosomal genes. Together, ITS1 and ITS2 are approximately 483 base pairs (bp) long in $P$. sativa (Downie and Katz-Downie 1996).

The nuclear rDNA ITS region has been used frequently in lower-level phylogenetic analyses in plants because of its ease of amplification and high mutation rate. ITS is also useful as a species barcode for angiosperms (Li et al. 2011), and adequate intraspecific and interspecific variation exists at this locus to delineate species within the family Apiaceae (Liu et al. 2014). Although ITS has been useful at infrageneric-level analyses, it can also be effective in providing information about population genetic structure (e.g., Besnard et al. 2007; Gao et al. 2012; Lorenz-Lemke et al. 2005). Because it occurs in the nuclear genome, ITS is biparentally inherited and recombines, so it has the potential to reveal recent gene flow and hybridization events.

The cpDNA psbM-trn T locus is a highly variable noncoding region, approximately $1,400 \mathrm{bp}$ long in Apiaceae (Downie and Jansen 2015). The chloroplast genome is haploid, nonrecombinant, and maternally inherited and can be informative for intraspecific phylogenetic analysis, especially over a large geographic area (Ouborg et al. 1999). cpDNA has a different evolutionary rate compared with nuclear DNA and, because it is maternally inherited, measures of gene flow are not confounded by reticulation (McCauley 1995). Both regions have been previously used together (Gao et al. 2010) and have the potential to elucidate the genetic structure of globally invasive plants.

DNA Extraction, Amplification, and Sequencing. Wholegenomic DNA was amplified from approximately $20 \mathrm{mg}$ of dried leaf material using a Qiagen DNeasy Plant Mini kit according to the manufacturer's directions (Qiagen Inc., Valencia, CA). ITS1 (18S to $5.8 \mathrm{~S}$ ) and ITS2 (5.8S to $28 \mathrm{~S}$ ) were polymerase chain reaction (PCR)-amplified separately using previously published primers (Table 2 ). The $5.8 \mathrm{~S}$ region that joins ITS1 and ITS2 is highly conserved and, therefore, was not completely sequenced. The cpDNA $p s b M$-trnT locus contains intervening genes $\operatorname{trn} D, \operatorname{trn} Y$, and $\operatorname{trn} E$, and the spacers between $p s b M$ and $\operatorname{trn} E$ and between 


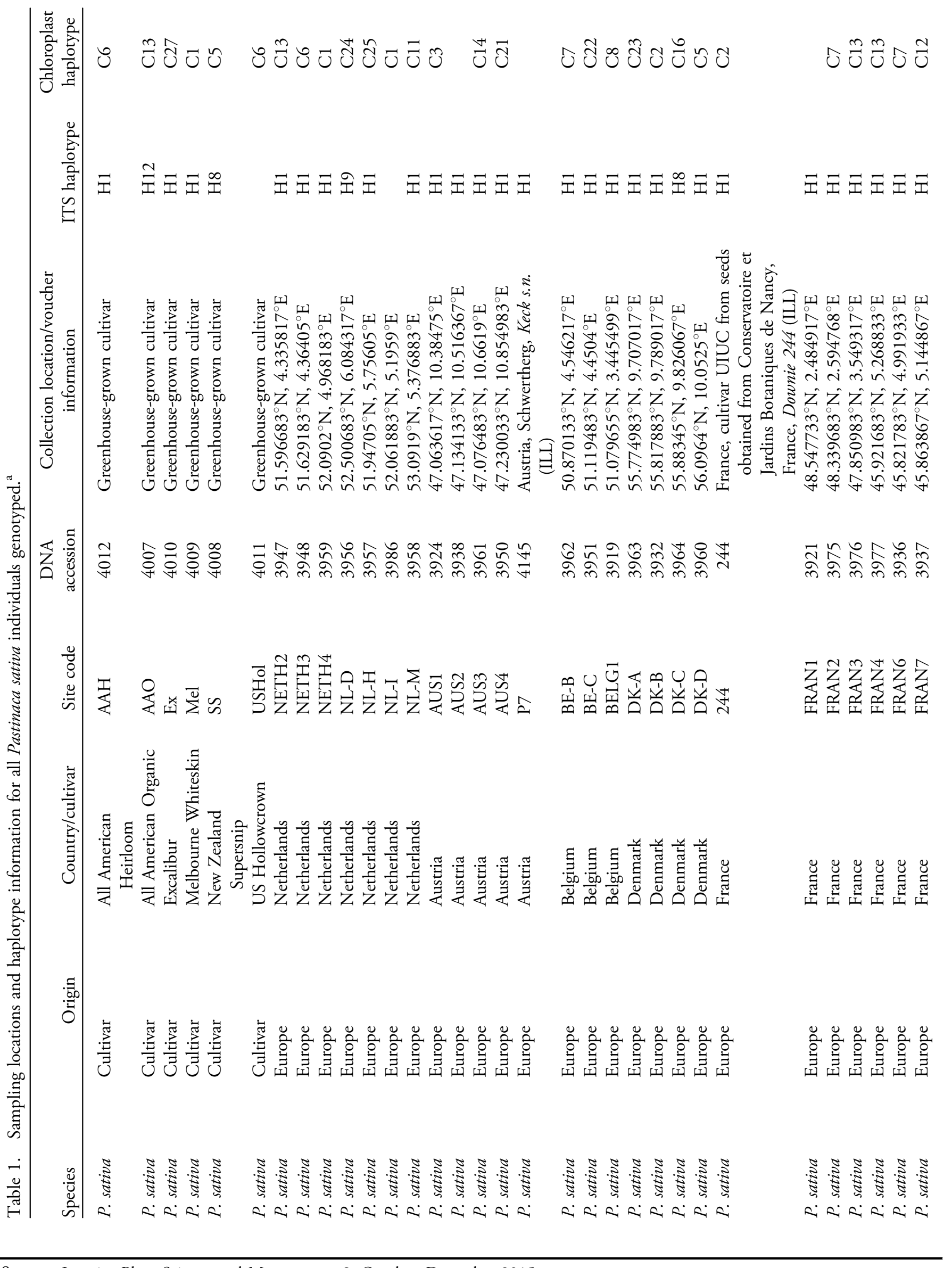

418 - Invasive Plant Science and Management 8, October-December 2015 


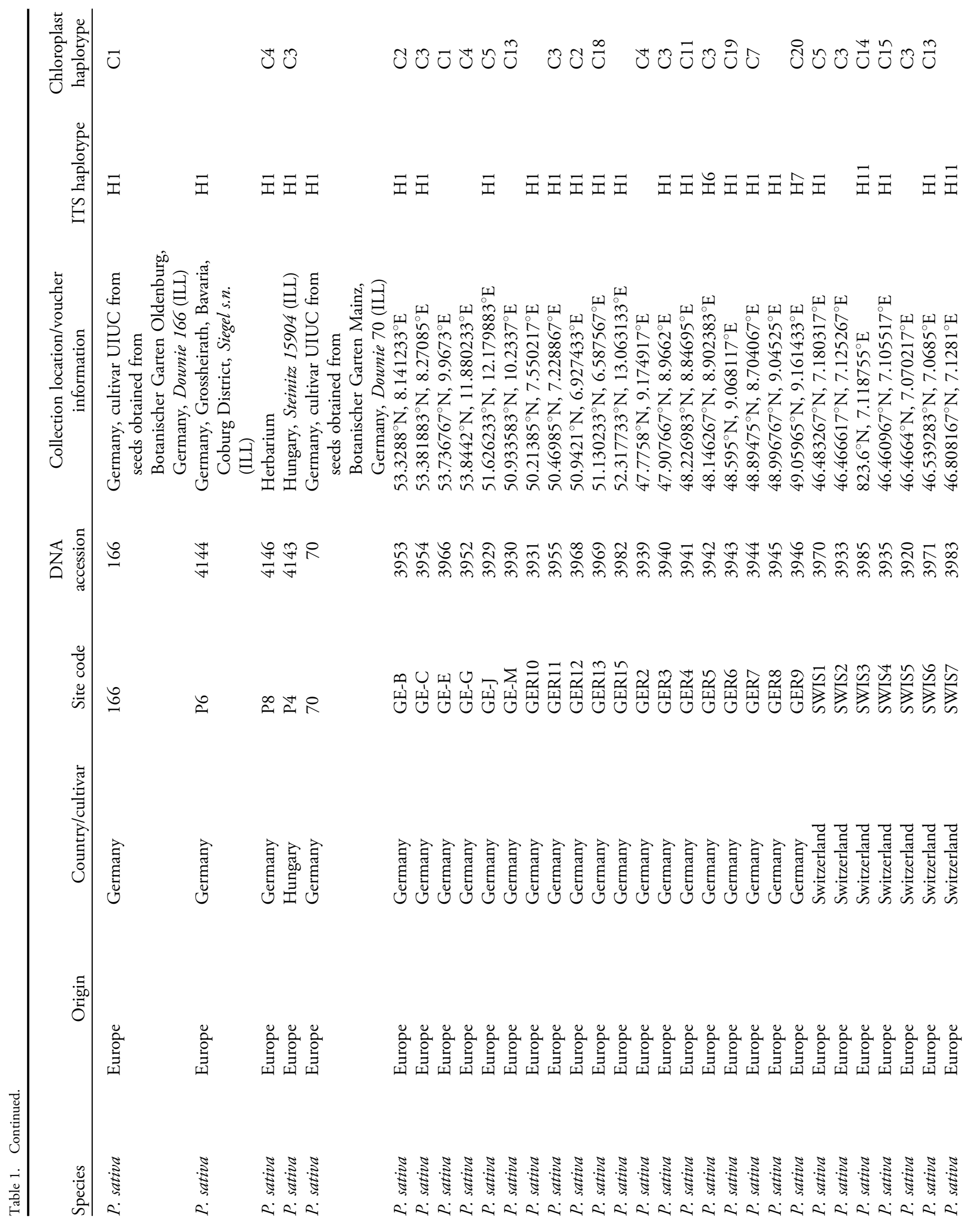




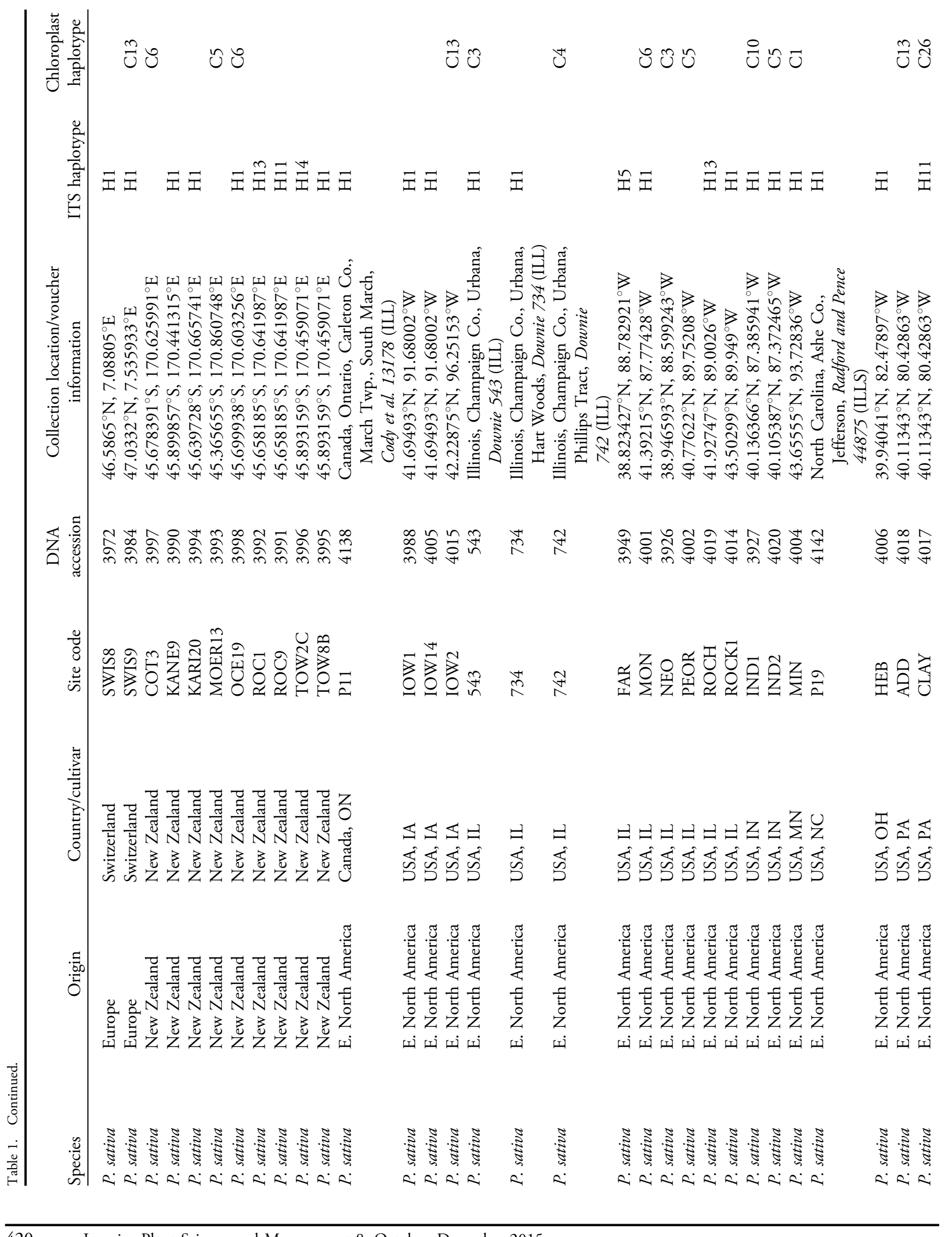

420 - Invasive Plant Science and Management 8, October-December 2015 


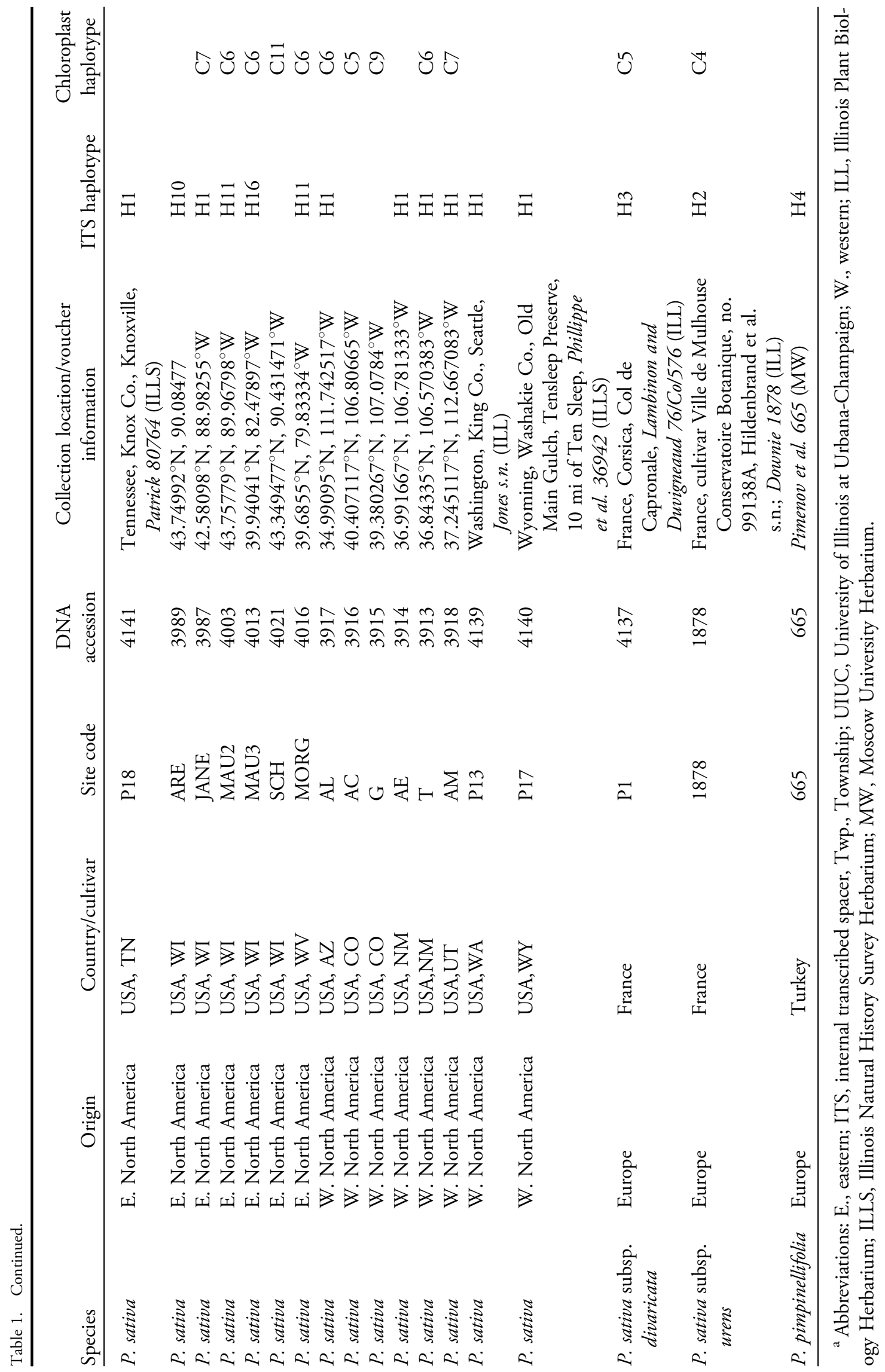


Table 2. Polymerase chain reaction primers for internal transcribed spacer (ITS) and chloroplast DNA (cpDNA) psbM-trnT.

\begin{tabular}{|c|c|c|c|}
\hline Locus & Primer and location & Reference & Primers \\
\hline \multirow[t]{4}{*}{ ITS } & $18 \mathrm{~S} F 5^{\prime}$ & Feist and Downie 2008 & TAG AGG AAG GAG AAG TCG TAA \\
\hline & 5.8S R $3^{\prime}$ & Feist and Downie 2008 & ATA CTT GGT GTG AAT TGC AGA A \\
\hline & $5.8 \mathrm{~S}(\mathrm{ITS}-3 \mathrm{~N}) \mathrm{F} 5^{\prime}$ & Spalik and Downie 2006 & CGA TGA AGA ACG TAG CGA AAT \\
\hline & $28 \mathrm{~S}(\mathrm{C} 26 \mathrm{~A}) \mathrm{R} 3^{\prime}$ & Wen and Zimmer 1996 & AGC GGA GGA AAA GAA AC \\
\hline \multirow[t]{4}{*}{ cpDNA } & $p s b M$ F $5^{\prime}$ & Modified from Shaw et al. (2005) & AGC AAT AAA TGC RAG AAT ATT TAC TTC CAT \\
\hline & trnE R 3' & Modified from Shaw et al. (2005) & TCC TGT AGA GAG AAA GTT CCT G \\
\hline & $\operatorname{trn} D \mathrm{~F} 5^{\prime}$ & Modified from Shaw et al. (2005) & ACC AAT TGA ACT ACA ATC CC \\
\hline & $\operatorname{trn} T$ R 3' & Shaw et al. (2005) & CTA CCG CTG AGT TAA AAG GG \\
\hline
\end{tabular}

$\operatorname{trn} E$ and $\operatorname{trn} T$ were amplified separately and used to assemble a complete $p s b M-\operatorname{trn} T$ contig after sequencing. PCR primers for the chloroplast region are listed in Table 2.

Each $25-\mu \mathrm{l}$ PCR reaction included sterile water $(9.5 \mu \mathrm{l}$ in ITS reactions; $10.75 \mu \mathrm{l}$ in cpDNA reactions), $5.0 \mu \mathrm{l}$ of $5 \times$ of colorless GoTaq Flexi buffer (Promega Corp., Madison, WI), $4.0 \mu \mathrm{l}$ of deoxynucleotides (dNTPs; each dNTP at $1.25 \mu \mathrm{M}$; Invitrogen Corp., Carlsbad, CA), $3.0 \mu \mathrm{l}$ of $\mathrm{MgCl}_{2}(25 \mathrm{mM}), 0.5 \mu \mathrm{l}$ of each primer $(20 \mu \mathrm{M})$, GoTaq Flexi DNA polymerase $(0.5 \mu \mathrm{l}$ in ITS reactions; $0.25 \mu \mathrm{l}$ in cpDNA reactions; Promega Corp.), and $1.0 \mu \mathrm{l}$ of unquantified template DNA. DMSO (dimethyl sulfoxide; $1.25 \mu \mathrm{l}$ ) was added to the ITS reactions to relax secondary structures. For samples that were difficult to amplify, template DNA was diluted $1: 10$ or $1: 100$ to reduce contaminant concentration. The PCR protocol is outlined in Downie and Katz-Downie (1996) for ITS and Shaw et al. (2005) for $p s b M-t r n T$. For some cpDNA amplifications, Taq polymerase was replaced by a high-fidelity Phusion polymerase (New England BioLabs Inc., Ipswich, MA) in 20- $\mu$ l reactions with protocols as specified by the manufacturer. The Phusion PCR protocol is as follows: initial denaturation for $30 \mathrm{~s}$ at $98 \mathrm{C}$, followed by 35 cycles of $10 \mathrm{~s}$ at $98 \mathrm{C}$, $10 \mathrm{~s}$ at $58 \mathrm{C}$, and $30 \mathrm{~s}$ at $72 \mathrm{C}$.

PCR products were purified using the Exo-Sap method: $2.25 \mu \mathrm{l}$ sterile water, $0.25 \mu \mathrm{l}$ exonuclease I (Exo; 20 units/ $\mu \mathrm{l}$, New England BioLabs), and $0.50 \mu \mathrm{l}$ shrimp alkaline phosphatase (SAP; 1 unit/ $\mu$ l, Promega Corp.) were combined and added directly to each $25-\mu$ reaction tube, then incubated for $30 \mathrm{~min}$ at $37 \mathrm{C}$ followed by $15 \mathrm{~min}$ at $80 \mathrm{C}$ to inactivate the enzymes. For some samples, SAP was replaced with Antarctic Phosphatase (New England BioLabs).

Sequencing reactions were performed using the $\mathrm{ABI}$ Prism BigDye Terminator ver. 3.1 Ready Reaction Cycle Sequencing kit (Applied Biosystems, Foster City, CA). Primers used for PCR amplification were also used for forward and reverse sequencing. Each $10-\mu \mathrm{l}$ reaction included $1 \mu \mathrm{l}$ ultrapure water, $2 \mu \mathrm{l}$ sequencing buffer, $4 \mu \mathrm{l}$ glycerol, $1.5 \mu \mathrm{l}$ of the forward or reverse primer $(10 \mathrm{pM})$, and $0.5 \mu \mathrm{l}$ of BigDye. The sequencing reaction included initial denaturation for $1 \mathrm{~min}$ at $95 \mathrm{C}$, followed by 35 cycles of $15 \mathrm{~s}$ at
$95 \mathrm{C}, 5 \mathrm{~s}$ at $45 \mathrm{C}$, and $4 \mathrm{~min}$ at $60 \mathrm{C}$. Visualization of sequences was carried out using an ABI 3730XL highthroughput DNA capillary sequencer at the UIUC Keck Biotechnology Center.

Data Analysis. Forward and reverse sequences were assembled, and disagreements were manually corrected in Sequencher ver. 5.2 (Gene Codes Corporation, Ann Arbor, MI, http://www.genecodes.com). All ambiguous nucleotide positions (double chromatogram peaks) that might have been heterozygous alleles were coded with an N. It is unlikely that our treatment of ITS heterozygotes influences our analyses because ITS heterozygotes were relatively uncommon. Chloroplast sequences psbM-trnE and trnE$\operatorname{trn} T$ were assembled into one contig using default parameters. Exported sequences from all samples were aligned with MUSCLE ver. 3.5 (Edgar 2004) using the default parameters. Sequences for $P$. sativa subsp. divaricata, $P$. sativa subsp. urens, and $P$. pimpinellifolia (Downie and Katz-Downie 1996; Logacheva et al. 2008) were included in the data matrices for comparison to wild parsnip sequences.

Because the complete $5.8 \mathrm{~S}$ region that separates ITS1 and ITS2 was not sequenced, data matrices for ITS1 and ITS2 were concatenated in MESQUITE (Maddison and Maddison 2011; http://mesquiteproject.org) after sequence alignment.

Standard molecular diversity indices were calculated for both loci using DnaSP (Rozas 2009; http://www.ub.edu/ dnasp/). Diversity calculations included the number of haplotypes, the number of segregating (polymorphic) sites, the nucleotide diversity, and haplotype diversity of all variable nucleotide sites in each locus. Sequence divergence between geographic regions was inferred using pairwise exact tests with 10,000 Markov chain Monte Carlo (MCMC) chains implemented in ARLEQUIN ver. 3.5 (Excoffier and Lischer 2010; http://cmpg.unibe.ch/software/arlequin35/). Exact tests for population differentiation are based on the nonparametric Fisher's exact test, which is used to determine whether an association exists between the counts of two variables. In the case of populations, exact tests compare geographic regions based on the occurrence of haplotypes 
Table 3. Molecular diversity indices estimated from internal transcribed spacer (ITS) and chloroplast sequences from wild parsnips on three continents and cultivated parsnips.

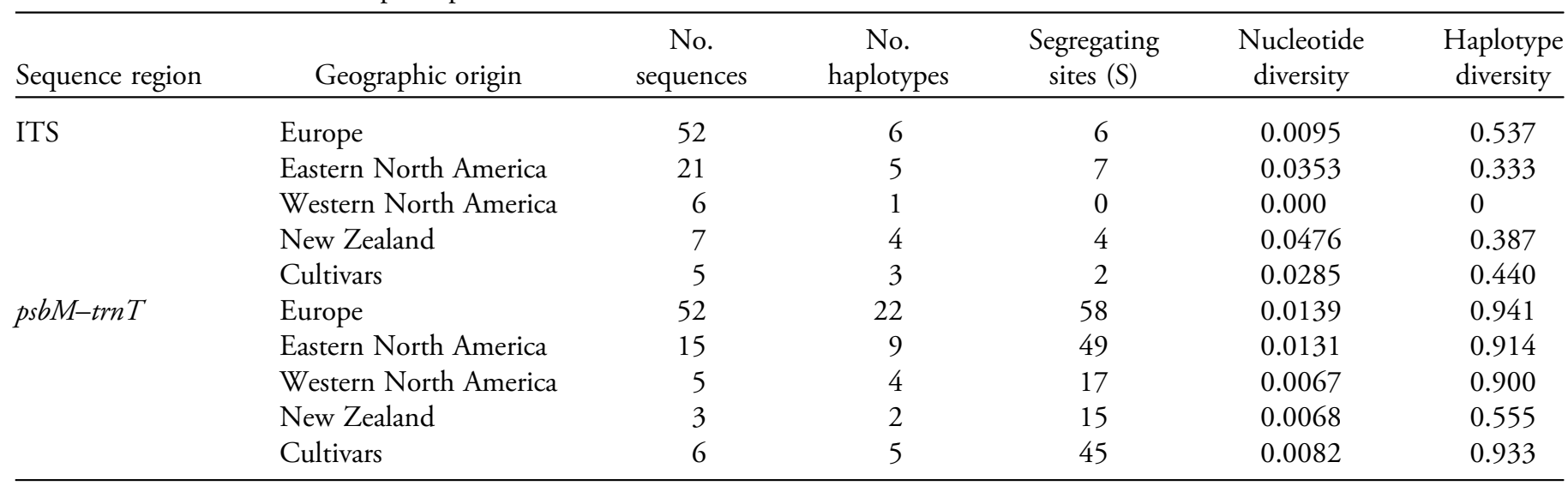

(Raymond and Rousset 1995). The exact test is a useful measure of differentiation when sample sizes are unbalanced (Goudet et al. 1996). Haplotype networks were constructed in HapStar (Teacher and Griffiths 2011) from minimum spanning trees obtained in ARLEQUIN.

\section{Results and Discussion}

We successfully amplified and sequenced the ITS locus for 91 individuals (GenBank accession numbers: KT766558-KT766731) and the psbM-trnT locus for 81 individuals. Alignment of concatenated ITS1 and ITS2 sequences contained 483 nucleotide positions, of which 28 were polymorphic in all sequences analyzed. The polymorphisms were all single-nucleotide polymorphisms (SNPs), with seven SNPs parsimony-informative. In wild parsnips, 19 sites were polymorphic, and four of these were parsimony-informative. In cultivated parsnips, two sites were polymorphic, and none were parsimony-informative. Individuals were separated into 14 haplotypes (hereby denoted as $\mathrm{H} 1$ to H14; Table 1).

Alignment of the concatenated $p s b M-\operatorname{trn} T$ region contained 1,464 nucleotide positions and 14 SNPs, and all SNPs were parsimony-informative. Most of the variation in this region is a result of nine multiallelic insertion-deletion polymorphisms with an average indel length of 9.4 bp. Wild parsnips had all of the 14 SNP and 9 indel polymorphisms, whereas cultivars had six SNP and three indel polymorphisms. Combined indel and SNPs polymorphisms separated all 81 individuals into 27 haplotypes (hereby denoted as $\mathrm{C} 1$ to $\mathrm{C} 27$; Table 1 ).

Most individuals (79\%) shared ITS haplotype H1. H11 was the second most-common haplotype, shared by $5 \%$ of all individuals, and all other observed ITS haplotypes were unique to one or two individuals. Europe had the highest number of ITS haplotypes (Table 3). Eastern North America had two unique haplotypes and two shared with New
Zealand (H11 and H13; Figure 1) in addition to the most-common haplotype, $\mathrm{H} 1$.

All six western North American parsnips samples were H1. The two subspecies of wild parsnip from Europe, $P$. sativa subsp. urens and $P$. sativa subsp. divaricata, had unique ITS haplotypes and, as expected, the ITS sequence for $P$. pimpinellifolia was different from all $P$. sativa sequences. Three cultivars, $P$. sativa 'All-American Heirloom', $P$. sativa 'Excalibur', and $P$. sativa 'Melbourne Whiteskin', belonged to the ubiquitous H1. One New Zealand cultivar (P. sativa 'New Zealand Supersnip') shared haplotype H8 with the European wild parsnips. European parsnips consisted predominantly of the $\mathrm{H} 1$ haplotype but had more unique haplotypes $(n=6)$ than any other region.

ITS has been successfully used as a molecular marker for intraspecific studies of many plants, but for some, it has shown very little variation. For example, Gao et al. (2012) reported 19 distinct ITS haplotypes in the endemic Tibetan species stonecrop [Rhodiola alsia (Fröed.) S.H. Fu] (Crassulaceae) with strong branch support for the evolutionary relationship between haplotypes, whereas Soltis and Kuzoff (1993) found very little variation in ITS1 in populations of Gray's biscuitroot [Lomatium grayi (J.M. Coult. \& Rose) J.M. Coult. \& Rose] and Slickrock biscuitroot [Lomatium laevigatum (Nutt.) J.M. Coult. \& Rose] (Apiaceae). ITS is used more frequently for inferring infrageneric relationships, such as within the Apiaceae genera cowparsnip (Heracleum spp.) (Yu et al. 2011), burnet saxifrage (Pimpinella spp.) (Magee et al. 2010), and angelica (Angelica spp.) (Feng et al. 2009). In this study, ITS clearly differentiated between $P$. sativa and $P$. pimpinellifolia and among the subspecies of $P$. sativa ( $P$. sativa subsp. urens and $P$. sativa subsp. divaricata), but variation among $P$. sativa individuals was low. These findings suggest that ITS in $P$. sativa might evolve too slowly to differentiate cultivated and wild parsnips, and the introduction and cultivation of $P$. sativa might have occurred too recently for ITS to be a useful marker in this system. 
Table 4. Pair-wise comparisons of differentiation (exact tests) among geographic regions calculated from divergence at the ribosomal internal transcribed spacer (ITS) and chloroplast DNA (cpDNA) locus. P values derived from 10,000 Monte chain Monte Carlo runs are depicted in the table and significant differences at $\mathrm{P}<0.05$ are denoted by an asterisk $\left(^{*}\right)$. The two subspecies are Pastinaca sativa ssp. divaricata and Pastinaca sativa ssp. urens. $^{\text {a }}$

\begin{tabular}{lllccc}
\hline & & Europe & Eastern NA & Western NA & New Zealand \\
\hline \multirow{2}{*}{ ITS } & Eastern NA & $0.038^{*}$ & & & \\
& Western NA & 1.000 & 0.799 & 0.560 & 1.000 \\
& New Zealand & 0.050 & 0.529 & 0.180 & 0.167 \\
\multirow{2}{*}{ cpDNA } & Cultivar & 0.109 & 0.259 & $0.012^{*}$ & 0.186 \\
& Subsp. & $0.002^{*}$ & $0.011^{*}$ & & \\
& Eastern NA & 0.423 & & & \\
& Western NA & 0.195 & 0.927 & 1.000 & 1.000 \\
& New Zealand & 0.231 & 1.000 & 1.000 & 0.606 \\
& Cultivar & 0.311 & 0.977 & 0.806 & 0.864 \\
\hline
\end{tabular}

${ }^{a}$ NA, North America; subsp., subspecies.

There were substantially more chloroplast haplotypes (chlorotypes) than ITS haplotypes; 27 chlorotypes were present in 81 samples. Chloroplast markers separated individuals into at least two distinct lineages, groups $\mathrm{A}$ and $\mathrm{B}$ (Figure 2). Of the 22 chlorotypes found in Europe, 15 occurred nowhere else. Eastern North American parsnips shared $86 \%$ of their haplotype diversity (seven chlorotypes) with European parsnips and had two unique chlorotypes (Figure 2). Western North American parsnips had one unique chlorotype (C9) and shared three chlorotypes (C5, C6, and C7) with Europe and eastern North America. Two chlorotypes (C5 and C6) were recovered from New Zealand parsnips, both of which also occurred in Europe, North America, and cultivars. Cultivated parsnips shared $80 \%$ of their chlorotype diversity with Europe and eastern North America. One cultivar, P. sativa 'Excalibur', had a unique chlorotype (C27). Pastinaca sativa subsp. divaricata had the ubiquitous $\mathrm{C} 5$ chlorotype and $P$. sativa subsp. urens shared C4 with European wild parsnips.

High levels of haplotype diversity were found in all introduced geographic regions, even though western North America and New Zealand provided disproportionally fewer samples from fewer populations (Table 3). Nucleotide diversity was also similar between all regions (Table 3 ), indicating no loss of genetic variation after introduction. Numerous studies comparing neutral genetic variation between native and invasive populations suggest that genetic diversity in the invasive range is often the same as or higher than that in the native range (Bossdorf et al. 2005). Higher genetic variation is often a consequence of multiple introductions from genetically diverse native populations. For example, the population genetic structure of the brown anole lizard Anolis sagrei in Florida shows that at least eight different introductions from all over the world are responsible for the extant diversity in its invasive range (Kolbe et al. 2004). Similarly, Genton et al. (2005) found that the invasive common ragweed (Ambrosia artemisiffolia L.) (Asteraceae) in France originated from multiple sources in North America. For wild parsnips, two possibilities exist in terms of multiple introductions: the plant may have been introduced from what has been traditionally considered the European wild parsnip, $P$. sativa subsp. sylvestris, or invasive populations may consist of individuals that have escaped from multiple cultivars. Few studies have examined invasive plants that are garden or agricultural escapees, but one such study found that high genetic diversity of invasive European olive (Olea europaea L. ssp. europaea) (Oleaceae) in Australia is a consequence of the introduction of multiple cultivars in the invasive range (Besnard et al. 2007).

Exact tests showed no overall geographic differentiation at the cpDNA locus among geographic regions and no differentiation between cultivars and wild parsnips (exact test for overall differentiation, $\mathrm{P}=0.79$, pairwise tests in Table 4). However, the ITS locus showed that plants in Europe may be genetically distinct from those in eastern North America (exact test for overall differentiation, $\mathrm{P}=0.0007$, pairwise tests in Table 4). In spite of the extremely high occurrence of haplotype H1 in both regions, eastern North America had two haplotypes, H11 and H13, which were not found in European samples in this study. The lack of genetic divergence in introduced populations suggests rapid range expansion, which is typical for many weedy species.

Even though there is no evidence to suggest that cultivars are genetically distinct from wild parsnips, the distribution of haplotypes suggests that some chlorotypes (group B; Figure 2) are unique to wild parsnip populations. These chlorotypes may represent the original wild form, $P$. sativa subsp. sylvestris, whereas group A might represent $P$. sativa subsp. sativa, the cultivated parsnip. European parsnips had a much greater diversity of haplotypes, with at least 15 haplotypes unique to this geographic region, which is expected for 


\section{Europe (native)}

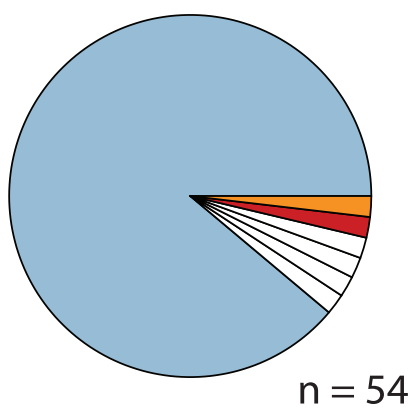

\section{E. North America $\quad$ W. North America}

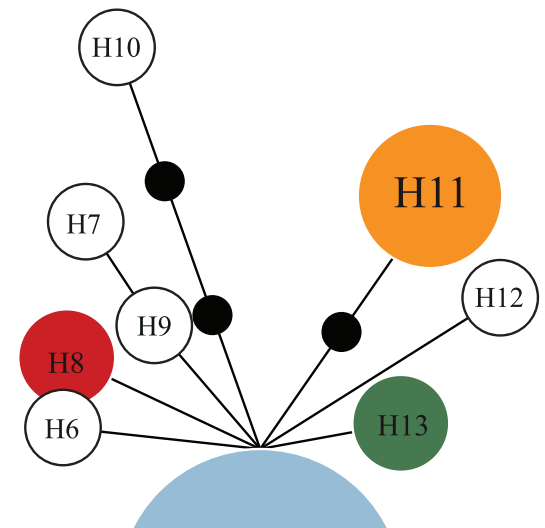

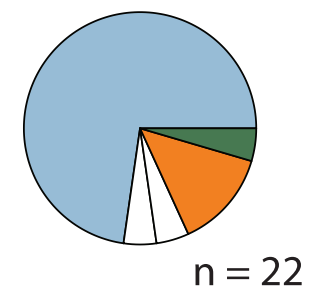

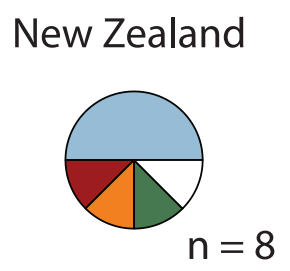

Cultivars

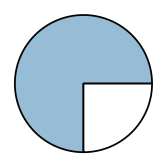

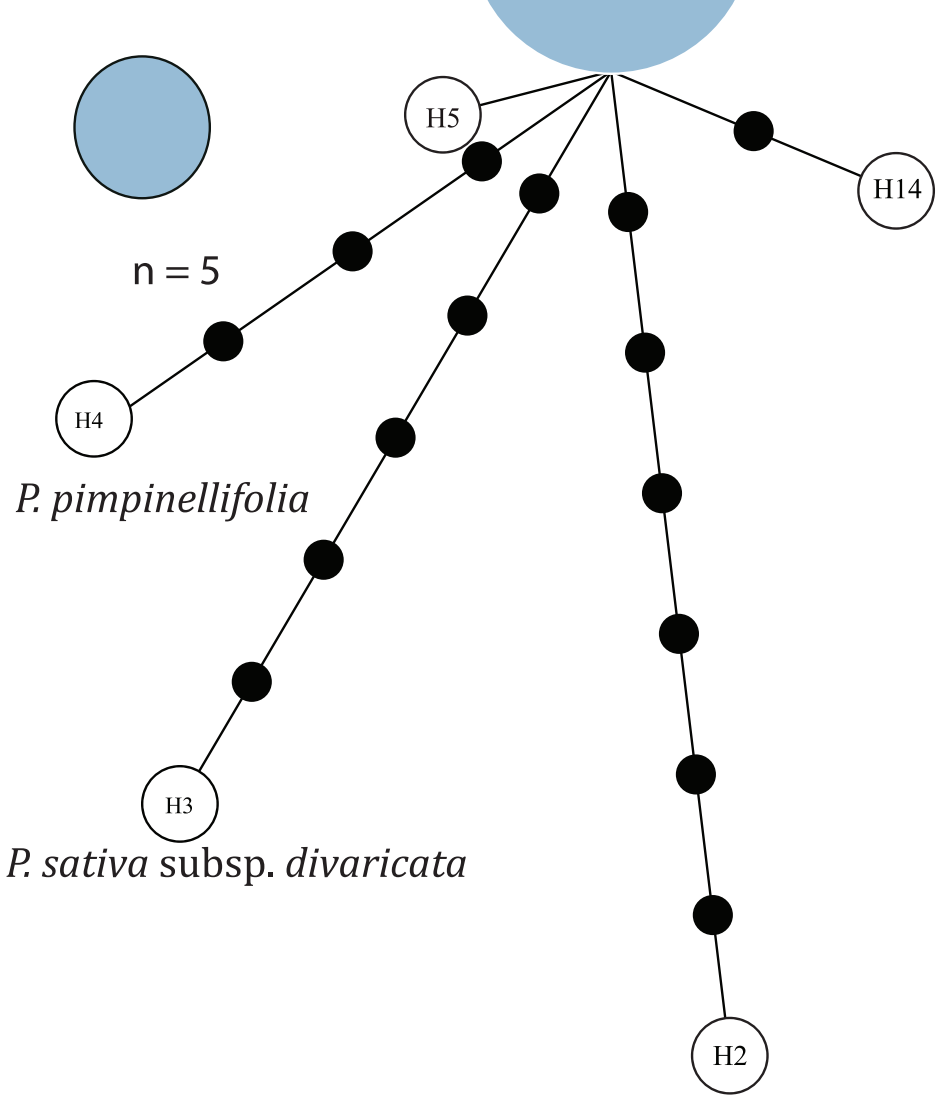

P. sativa subsp. urens

Figure 1. The relationship between internal transcribed spacer haplotypes and the distribution of haplotypes in Europe, North America, New Zealand, and in cultivars. The size of each circle is proportional to the number of individuals. Branches between haplotypes are proportional to the number of mutational steps. Black circles depict missing haplotypes. Only haplotypes shared among regions are assigned a color. (Color for this figure is available in the online version of this article.)

the native range. Interestingly, nearly half of Europe's wild parsnips have chlorotypes shared with cultivars, suggesting that, even in the native range, wild parsnip populations are a combination of escaped cultivars and originally wild $P$. sativa subsp. sylvestris chlorotypes. At least two of these noncultivar chlorotypes (C3 [blue] and C7 [purple] Figure 2) also occurred with some frequency in North American populations, suggesting that either escape from cultivation or introduction from Europe or both may have been responsible for the invasion of wild parsnips in North America. In 


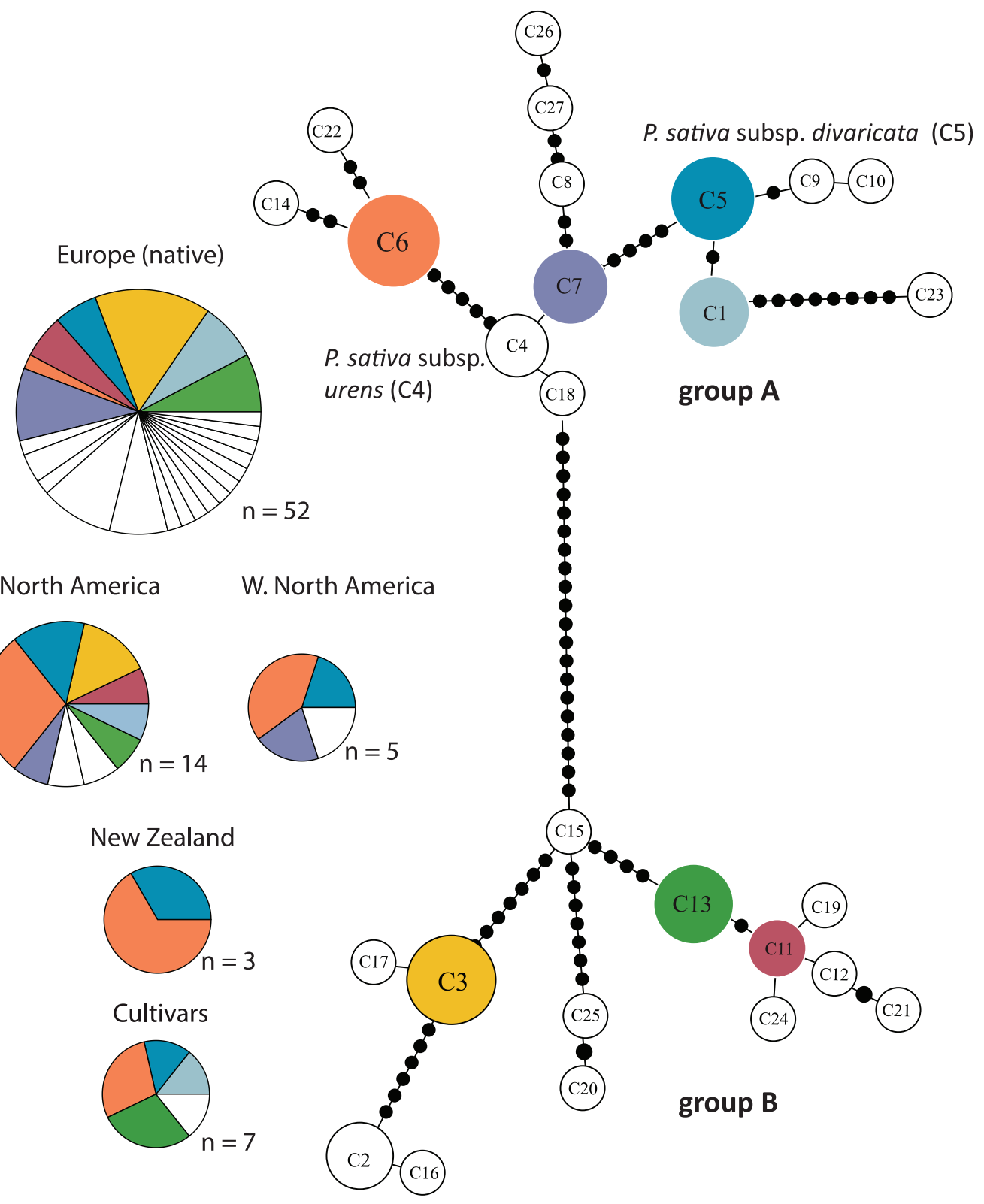

Figure 2. The relationship among $p s b M-\operatorname{trn} T$ haplotypes and the distribution of haplotypes in Europe, North America, New Zealand, and in cultivars. The size of each circle is proportional to the number of individuals. Branches between haplotypes are proportional to the number of mutational steps. Black circles depict missing haplotypes. Only haplotypes shared among regions are assigned a color. (Color for this figure is available in the online version of this article.)

New Zealand, both haplotypes were shared with cultivars (i.e., 'New Zealand Supersnip,' 'US Hollow Crown' and 'All-American Heirloom'), suggesting that New Zealand populations are primarily escapees from cultivation.

The differences in morphology and chemistry between wild and cultivated parsnips are likely maintained by strong herbivore selection for increased defenses, even though wild and cultivated parsnips do not appear to be genetically distinct for the markers used in this study. At least in North America, parsnips are not commercially cultivated on a large scale, and these biennial plants are usually harvested for the root before flowering, making recent hybrids unlikely in most of the sampled wild populations. Herbivore-mediated selection for chemical traits can act rapidly in wild parsnip populations (Jogesh et al. 2014; Zangerl and Berenbaum 2005; Zangerl et al. 2008), so it is likely that strong selection maintains the apparent morphological differences between wild and cultivated parsnips.

The closely related wild carrot, Daucus carota, represents a similar system where the species has been cultivated 
throughout the world and wild forms occur as a globally invasive species. In comparison to parsnips, wild carrots are genetically distinct from cultivated carrots (Bradeen et al. 2002; Iorizzo et al. 2013; Shim and Jorgensen 2000). In view of the fact that the two species were probably domesticated at the same time, the clear genetic distinction between wild and cultivated forms of carrot in contrast to the lack of differentiation in parsnips may reflect differences in the history and manner of domestication. Based on recent evidence from a large SNP data set, carrots appear to have been domesticated from yellow- and purple-rooted wild carrots in central Asia, which are genetically distinct from European wild carrots (Iorizzo et al. 2013). The modern cultivars of parsnips, on the other hand, are known to have been bred from European wild parsnips and hybridizations between the two may have occurred at a higher frequency in the process of cultivation (e.g., the cultivar P. sativa 'Gladiator' is a hybrid), reducing the genetic distance between wild and cultivated forms. Although the morphological and chemical distinction between wild and cultivated parsnips is a consequence of herbivore-mediated natural selection, the phenotypic differences between wild and cultivated carrot are a result of selection for specific cultivar genotypes (Grebenstein et al. 2011). A recent large-scale study comparing wild and domesticated carrots showed diversifying selection in at least 27 markers (Grezebelus 2014). Wild carrots in North America are more closely related to wild carrots in Europe, suggesting that introduction from Europe, and not escape from cultivation, is primarily responsible for the colonization of this invasive plant. In wild parsnips as well, it appears that accidental introduction form Europe is at least partly responsible for the high diversity of chlorotypes observed in North America.

The lack of genetic differentiation among isolated geographic regions suggests that the historical source of all invasive populations is the same, and not enough time has passed for the fixation of alleles at this locus. It is also plausible, although less likely, that contemporary gene flow among geographic regions occurs with some frequency. Gene flow among parsnip populations within a geographic region is expected to be high because of the predominantly roadside distribution of this plant and the ease with which its seeds can be carried long distances by vehicles. Pickering and Mount (2010) found that seeds from 372 exotic plant species have been collected from clothing, equipment, or vehicles, indicating that long-distance, human-mediated dispersal can occur on a regular basis. In some species, admixture is associated with global trade. For example, levels of admixture in the Chinese mitten-crab (Eriocheir sinensis) were strongly correlated with shipping volume, an association expected if human-mediated dispersal was its primary means of gene flow between continental Europe and the United Kingdom (Herborg et al. 2007). Thus, it is reasonable to hypothesize that high rates of gene flow via multiple contemporary introductions of $P$. sativa in its invasive range may contribute to the lack of genetic differentiation between continents.

This study provides preliminary evidence suggesting that wild and cultivated parsnips are not genetically distinct. Invasive populations in all geographic regions harbor high genetic diversity, indicative of multiple introductions or high rates of gene flow. Only two loci were analyzed with limited sampling in this study and analyses of multiple loci, especially diploid loci with higher mutation rates, such as microsatellites, can help elucidate the source or sources and routes of invasion and the extent of gene flow and admixture within and among continents.

\section{Acknowledgments}

This work was supported by funds provided by the $\mathrm{H}$. $\mathrm{H}$. Ross Memorial Award for Systematic Biological Research, the Francis M. and Harlie M. Clark Research Support Grant from the School of Integrative Biology, UIUC, the Tyler Prize for Environmental Achievement, and National Science foundation grant and NSFDEB1457731 awarded to May Berenbaum, and the Downie Katz-Downie research fund. Thanks to Yue Xu for help with the molecular work, Maksim Sergeyev for DNA extractions, and Paul Ode and Margaret Stanley for sample collections.

\section{Literature Cited}

Averill KM, DiTommaso A (2007) Wild parsnip (Pastinaca sativa): a troublesome species of increasing concern. Weed Technol 21:279-287

Barnaud A, Kalwij JM, McGeoch MA, van Vuuren BJ (2013) Patterns of weed invasion: evidence from the spatial genetic structure of Raphanus raphanistrum. Biol Invasions 15:2455-2465

Berenbaum MR, Zangerl AR, Nitao JK (1984) Furanocoumarins in seeds of wild and cultivated parsnip. Phytochemistry 23:1809-1810

Besnard G, Henry P, Wille L, Cooke D, Chapuis E (2007) On the origin of the invasive olives (Olea europaea L. Oleaceae). Heredity 99:608-619

Bossdorf O, Auge H, Lafuma L, Rogers W, Siemann E, Prati D (2005) Phenotypic and genetic differentiation between native and introduced plant populations. Oecologia 144:1-11

Bradeen JM, Bach IC, Briard M, le Clerc V, Grzebelus D, Senalik DA, Simon PW (2002) Molecular diversity analysis of cultivated carrot (Daucus carota L.) and wild Daucus populations reveals a genetically nonstructured composition. J Hortic Sci 127:383-391

Buckman J (1865) Science and Practice in Farm Agriculture. Hardwicke, London. Pp 1-8

De Andrés MT, Benito A, Pérez-Rivera G, Ocete R, Lopez MA, Gaforio L, Muñoz G, Cabello F, Martinez Zapater JM, Arroyo-Garcia R (2012) Genetic diversity of wild grapevine populations in Spain and their genetic relationships with cultivated grapevines. Mol Ecol 21:800-816

Downie SR, Katz-Downie DS (1996) A molecular phylogeny of Apiaceae subfamily Apioideae: evidence from nuclear ribosomal DNA internal transcribed spacer sequences. Am J Bot 83:234-251

Downie SR, Jansen RK (2015) A comparative analysis of whole plastid genomes from the Apiaceae: expansions and contraction of the inverted repeat, mitochondrial to plastid transfer of DNA, and identification of highly divergent noncoding regions. Syst Bot 40:336-351

Edgar RC (2004) MUSCLE: multiple sequence alignment with high accuracy and high throughput. Nucleic Acids Res 32:1792-1797 
Estoup A, Guillemaud T (2010) Reconstructing routes of invasion using genetic data: why how and so what? Mol Ecol 19:4113-4130

Excoffier L, Lischer HE (2010) Arlequin suite version 35: a new series of programs to perform population genetics analyses under Linux and Windows. Mol Ecol Res 10:564-567

Feng T, Downie SR, Yu Y, Zhang X, Chen W, He X, Liu S (2009) Molecular systematics of Angelica and allied genera (Apiaceae) from the Hengduan Mountains of China based on nrDNA ITS sequences: phylogenetic affinities and biogeographic implications. J Plant Res 122:403-414

Feist MAE, Downie SR (2008) A phylogenetic study of Oxypolis and Ptilimnium (Apiaceae) based on nuclear rDNA ITS sequences. Syst Bot 33:447-458

Gao Q, Zhang D, Duan Y, Zhang F, Li Y, Fu P, Chen S (2012) Intraspecific divergences of Rhodiola alsia (Crassulaceae) based on plastid DNA and internal transcribed spacer fragments. Bot J Lin Soc 168:204-215

GBIF Data Portal (2015) Biodiversity occurrence data. http://www.gbif. net. Accessed August 18, 2015

Genton B, Shykoff J, Giraud T (2005) High genetic diversity in French invasive populations of common ragweed Ambrosia artemisiffolia as a result of multiple sources of introduction. Mol Ecol 14:4275-4285

Goudet J, Raymond M, de Meeüs T, Rousset F (1996) Testing differentiation in diploid populations. Genetics 144:1933-1940

Grebenstein C, Choi YH, Rong J, De Jong TJ, Tamis WLM (2011) Metabolic fingerprinting reveals differences between shoots of wild and cultivated carrot (Daucus carota L.) and suggests maternal inheritance or wild trait dominance in hybrids. Phytochemistry 72:1341-1347

Grzebelus D, Iorizzo M, Senalik D, Ellison S, Cavagnaro P, Macko-Podgorni A, Heller-Uszynska K, Kilian A, Nothnagel T, Allender C, Simon PW, Baranski R (2014) Diversity genetic mapping and signatures of domestication in the carrot (Daucus carota L.) genome as revealed by Diversity Arrays Technology (DArT) markers. Mol Breed 33:625-637

Hedrick UP, Sturtevant EL (1972) Sturtevant's Edible Plants of the World, New York: Dover. 265 p

Herborg L, Weetman D, van Oosterhout C, Hanfling B (2007) Genetic population structure and contemporary dispersal patterns of a recent European invader the Chinese mitten crab Eriocheir sinensis. Mol Ecol 16:231-242

Iorizzo M, Senalik DA, Ellison SL, Grzebelus D, Cavagnaro PF, Allender C, Brunet J, Spooner D, Deynz A, Simon PW (2013) Genetic structure and domestication of carrot (Daucus carota subsp. sativus) (Apiaceae). Am J Bot 100:930-938

Jogesh T, Stanley MR, Berenbaum MR (2014) Evolution of tolerance in an invasive weed after reassociation with its specialist herbivore. J Evol Biol 11:2334-2346

Juntilla O (1976) Allelopathic inhibitors in seeds of Heracleum laciniatum. Physiol Plant 36:374-378

Kolbe J, Glor R, Rodríguez-Schettino L, Lara A, Larson A, Losos J (2004) Genetic variation increases during biological invasion by a Cuban lizard. Nature 431:177-181

Li DZ, Gao LM, Li HT, Wang H, Ge XJ, Liu JQ, Chena ZD, Zhoua SL, Chena SL, Yanga JB, Fua CX, Zenga CX, Yana HF, Zhua YJ, Suna YS, Chena SY, Zhaoa L, Wanga K, Yanga T, Duana GW (2011) Comparative analysis of a large dataset indicates that internal transcribed spacer (ITS) should be incorporated into the core barcode for seed plants. Proc Natl Acad Sci U S A 108:19641-19646

Liu J, Shi L, Han J, Li J, Lu H, Hou J, Zhou X, Meng F, Downie SR (2014) Identification of species in the angiosperm family Apiaceae using DNA barcodes. Mol Ecol Res 14:1231-1238

Logacheva MD, Valiejo-Roman CM, Pimenov MG (2008) ITS phylogeny of west Asian Heracleum species and related taxa of Umbelliferae-
Tordylieae WDJ Koch with notes on evolution of their $p s b A-t r n H$ sequences. Plant Syst Evol 270:139-157

Lombaert E, Guillemaud T, Thomas C, Lawson Handley L, Li J, Wang S, Pang H, Goryacheva I, Zakharov I, Jousselin E, Poland R, Migeon A, Van Lenteren JDE, Clercq P, Berkvens N, Jones W, Estoup A (2011) Inferring the origin of populations introduced from a genetically structured native range by approximate Bayesian computation: case study of the invasive ladybird Harmonia axyridis. Mol Ecol 20:4654-4670

Lorenz-Lemke AP (2005) Phylogeographic inferences concerning evolution of Brazilian Passiflora actinia and P. elegans (Passifloraceae) based on ITS (nrDNA) variation. Ann Bot 95:799-806

Maddison WP, Maddison DR (2011) Mesquite: a modular system for evolutionary analysis, Version 275. http://mesquiteprojectorg. Accessed March 15, 2014

Magee AR, van Wyk BE, Tilney PM, Downie SR (2010) Phylogenetic position of African and Malagasy Pimpinella species and related genera (Apiaceae: Pimpinelleae). Plant Syst Evol 288:201-211

McCauley DE (1995) The use of chloroplast DNA polymorphism in studies of gene flow in plants. Trends Ecol Evol 10:198-202

Menemen Y, Jury SL (2001) A taxonomic revision of the genus Pastinaca L. (Umbelliferae). Isr J Plant Sci 49:67-77

[NANSH] North American Network of Small Herbaria (2015) NANSH Web site. http://nansh.org/portal/. Accessed August 18, 2015

Ouborg NJ, Piquot Y, Van Groenendael JM (1999) Population genetics molecular markers and the study of dispersal in plants. J Ecol 87:551-568

Pickering C, Mount A (2010) Do tourists disperse weed seed? A global review of unintentional human-mediated terrestrial seed dispersal on clothing, vehicles, and horses. J Sustain Tour 18:239-256

Pysek P (2011) Ecological impacts of invasive alien plants: a meta-analysis of their effects on species communities and ecosystems. Ecol Lett 14:702-708

Pysek P, Richardson DM (2010) Invasive species environmental change and management and health. Annu Rev Environ Resour 35: 25-55

Pysek P, Jarodova V, Hulme PE, Pergl J, Hejda M, Schaffner U, Vilà M (2012) A global assessment of invasive plant impacts on resident species communities and ecosystems: The interaction of impact measures invading species' traits and environment. Glob Change Biol 18:1725-1735

Raymond M, Rousset F (1995) An exact test for population differentiation. Evolution 49:1280-1283

Ridley CE, Kim S, Ellstrand NC (2008) Bidirectional history of hybridization in California wild radish, Raphanus sativus (Brassicaceae), as revealed by chloroplast DNA. Am J Bot 95:1437-1442

Rozas J (2009) DNA sequence polymorphism analysis using DnaSP. Pages 337-350 in Posada D, ed. Bioinformatics for DNA Sequence Analysis; Methods in Molecular Biology Series. Volume 537. New York: Humana

Rubatzky VE, Quiros CF, Simon PW (1999) Carrots and Related Vegetable Umbelliferae. New York: CABI. 294 p

Schaal BA, Gaskin JF, Caicedo AL (2003) The Wilhelmina E Key 2002 invitational lecture: phylogeography haplotype trees and invasive plant species. J Hered 94:197-204

Shaw J, Lickey EB, Beck JT, Farmer SB, Liu W, Miller J, Siripun KC, Winder CT, Schilling EE, Small RL (2005) The tortoise and the hare II: relative utility of 21 noncoding chloroplast DNA sequences for phylogenetic analysis. Am J Bot 92:142-166

Shim SI, Jørgensen RB (2000) Genetic structure in cultivated and wild carrots (Daucus carota L.) revealed by AFLP analysis. Theor Appl Genet 101:227-233

Soltis P, Kuzoff R (1993) ITS sequence variation within and among populations of Lomatium grayi and L. laevigatum (Umbelliferae). Mol Phylogenet Evol 2:166-170 
Spalik K, Downie SR (2006) The evolutionary history of Sium sensu lato (Apiaceae): dispersal, vicariance, and domestication as inferred from ITS rDNA phylogeny. Am J Bot 93:747-761

Stahl E (1981) Variation of myristicin content in cultivated parsnip roots (Pastinaca sativa subspecies sativa var. hortensis). J Agric Food Chem 29:890-892

Sturtevant EL (1890) The history of garden vegetables. Am Nat 24:30-49

Teacher AGF, Griffiths DJ (2011) HapStar: automated haplotype network layout and visualization. Mol Ecol Resour11:151-153

Thompson GD, Bellstedt DU, Byrne M, Millar MA, Richardson DM, Wilson JR, Le Roux JJ (2012). Cultivation shapes genetic novelty in a globally important invader. Mol Ecol 21:3187-3199

Vilà M, Espinar JL, Hejda M, Hulme PE, Jarošik V, Maron JL, Pergl J, Schaffner U, Sun Y, Pyšek P (2011) Ecological impacts of invasive alien plants: a meta-analysis of their effects on species, communities and ecosystems. Ecol Lett 14:702-708

Weaver WW (1997) Heirloom Vegetable Gardening: A Master Gardener's Guide to Planting Seed Saving and Cultural History. New York: Henry Holt
Webb CJ (1978) Checklist of dicotyledons naturalised in New Zealand 1. Umbelliferae. N Z J Bot 16: 387-390

Wen J, Zimmer EA (1996) Phylogeny and biogeography of Panax L.(the ginseng genus, Araliaceae): inferences from ITS sequences of nuclear ribosomal DNA. Mol Phylogenet Evol 6:167-177

Yu Y, Downie SR, He X, Deng X, Yan L (2011) Phylogeny and biogeography of Chinese Heracleum (Apiaceae tribe Tordylieae) with comments on their fruit morphology. Plant Syst Evol 296:179-203

Zangerl AR, Stanley MC, Berenbaum MR (2008) Selection for chemical trait remixing in an invasive weed after reassociation with a coevolved specialist. Proc Natl Acad Sci USA 105:4547-4552

Zangerl A, Berenbaum M (2005) Increase in toxicity of an invasive weed after reassociation with its coevolved herbivore. Proc Natl Acad Sci USA 102:15529-15532

Received June 1, 2015, and approved September 30, 2015.

Associate Editor for this paper: John F. Gaskin, USDA-ARS 